\title{
Association between Body Mass Index and Cognitive Function among Chinese Nonagenarians/Centenarians
}

\author{
Yan Zhou $^{\mathrm{a}}$ Joseph H. Flaherty ${ }^{\mathrm{b}}$ Chang-Quan Huang ${ }^{\mathrm{a}}$ Zhen-Chan Lu ${ }^{\mathrm{a}}$ \\ Bi-Rong Dong a \\ ${ }^{a}$ Department of Geriatrics, West China Hospital, Sichuan University, Chengdu, China; ${ }^{b}$ Department of \\ Internal Medicine and Division of Geriatrics, St. Louis University School of Medicine, St. Louis, Mo., USA
}

\author{
Key Words \\ Cognitive function • Nonagenarians/centenarians • Body \\ mass index
}

\begin{abstract}
Aims: We examined the individual association between body mass index (BMI) and cognitive function among the very elderly. Methods: The present study analyzed data from a survey that was conducted on all residents aged 90 years or more from a district which had 2,311,709 inhabitants in 2005. The subjects were divided into 4 groups according to quartiles of BMI (<16.6, 16.6-18.9, 18.9-21.1 and $>21.1)$, and according to classification criteria of underweight, normal weight, overweight and obesity in BMI $(<18.5,18.5-23.0$, 23.0-27.5 and >27.5), respectively. Results: The subjects included in the statistical analysis were 211 men and 427 women. Those in the 3rd quartile of BMI (18.9-21.1) had higher cognitive function scores $(p<0.001)$ and were less likely to present possible dementia $(p=0.016)$ than the others. However, there was no difference in cognitive function scores $(p=0.350)$ or prevalence of possible dementia $(p=0.263)$ among obesity, overweight, normal weight and underweight groups. Conclusions: Concerning longevity in Chi-
\end{abstract}

nese, there is an association between BMI and cognitive function. BMI of around 20 (18.9-21.1) is associated with the lowest risk of prevalence of possible dementia and the highest cognitive function scores.

Copyright $\odot 2011$ S. Karger AG, Basel

\section{Introduction}

Recent epidemiological studies have associated midlife adiposity with increased risk for dementia in late life, especially Alzheimer's disease $[1,2]$. In particular, they made the following associations: (1) atrophy of temporal lobes and greater prevalence of dementia in elderly women with consistently greater body mass index (BMI; an indicator of body adiposity) throughout adulthood [3]; (2) brain atrophy with greater BMI in male and female adults in their 50s [4]; and (3) smaller hippocampal volumes in elderly adults with larger waist/hip ratios (a measure of body fat distribution) [5]. Moreover, several epidemiological studies have identified increased BMI in middle age as a risk factor for diagnosis of dementia a few decades later, especially in women [6-8]. These studies generally accounted for comorbid conditions such as

\section{KARGER}

Fax +4161306 1234

E-Mail karger@karger.ch

www.karger.com (c) $2011 \mathrm{~S}$. Karger AG, Basel

$1420-8008 / 10 / 0306-0517 \$ 26.00 / 0$

Accessible online at:

www.karger.com/dem
Bi-Rong Dong

Department of Geriatrics, West China Hospital, Sichuan University

Guoxuexiang 37

Chengdu, Sichuang 610041 (China)

Tel. +8618980601332

E-Mail hxzhouyan@hotmail.com 
hypertension, diabetes mellitus, etc. [2], suggesting that body fat has detrimental effects on brain integrity and function. Adiposity appears to have functional relevance because studies found worse learning, memory and executive functioning in obese versus nonobese older adults [9-11]. In addition, Gunstad et al. [12], in a study of young and middle-aged healthy adults, associated being overweight or obese with executive dysfunction. On the other hand, weight loss is common in elderly people with dementia, particularly those with Alzheimer's disease.

It is well known that aging is associated with changes in body composition, including an increase of fat mass and a decline in lean mass. Abdominal fat, largely caused by the accumulation of visceral fat, increases proportionally more with age than peripheral fat [13-16]. Many epidemiological and clinical studies have shown that excess abdominal visceral fat correlates with increased risk for hypertension, dyslipidemia and hyperglycemia [17-19]. Measurement of BMI in older individuals may not adequately reflect abdominal fat accumulation because of the concurrent decrease in muscle mass.

Increased BMI in middle age as a risk factor for diagnosis of dementia a few decades later [1,2], dementia as a risk factor for weight loss in elderly people [20-22], association between aging and cognitive decline, and association between aging and changes in body composition have all been confirmed [13-16]. From these we can conclude that in the long-lived subjects (aged 90 years or more), there is a close association between BMI and cognitive function, which may be different from that in general older adults (aged 60 years or more). However, to our knowledge, no population-based study has yet evaluated the association of BMI and cognitive function in the longlived subjects. To help shed light on this area, we examined the association between BMI and dementia in the long-lived subjects using data from a sample of Chinese nonagenarians and centenarians.

\section{Subjects and Methods}

\section{Study Subjects}

The methods have been reported previously $[23,24]$. In brief, on the basis of the Dujiangyan (located in Sichuan province, southwest China) 2005 census, a cross-sectional study for agerelated diseases was conducted in 870 long-lived subjects $(>90$ years), which was a part of the Project of Longevity and Aging in Dujiangyan (PLAD). The PLAD aimed to investigate the relationship between environments, lifestyle, genetics, cognitive function, longevity and age-related diseases. Volunteers were examined by trained professional physicians according to basic health criteria. And the results were filled-in on a standard form, the questionnaire on lifestyles and cognitive function [measured using the 30-item Mini-Mental State Examination (MMSE)]. We excluded those who did not complete the MMSE test, or had no information on their BMI. Overall, 21 men and 26 women were excluded from the study because they had already died or moved away from the area. Of 262 men and 561 women who were interviewed, 38 men and 125 women did not complete the MMSE test, 6 men and 17 women had no information on their BMI, and 3 men and 8 women both did not complete the MMSE test and had no information on their BMI. Finally, we included 638 participants (221 men, 427 women) in the analysis. Informed consent was obtained from all participants (as well as their legal proxies). The Research Ethics Committee of Sichuan University approved the study.

\section{Data Collection and Measurements}

\section{Assessment of Cognitive Function}

The methods of assessment of cognitive function have been reported previously $[23,24]$. Cognitive function was measured using the 30-item MMSE, which was a global test with components of orientation, attention, calculation, language and recall. To decrease methodological errors and assure methodological reliability, the administrator was given professional training which consisted of: (1) reviewing the MMSE procedure and grading system outlined in a short booklet and video, (2) observing a geriatrician conduct the MMSE on residents not part of the study and (3) receiving supervision while conducting the MMSE on residents not part of the study. The MMSE was administered to individuals who gave consent for study participation. The individuals were categorized as follows: possible dementia (scores between 0 and 18), mild cognitive impairment (scores between 19 and 24) and normal (scores between 25 and 30) [23, 24].

Because the MMSE relied heavily on visual and auditory abilities, especially at advanced ages $[25,26]$, there was a high prevalence of visual or hearing impairment among nonagenarians and centenarians. Twenty-eight men and 72 women did not complete the MMSE test due to visual or hearing impairment. To address this, these subjects were excluded when the data were analyzed. In the oldest-old sample, only 35 subjects had scores higher than 24 (30 in men, 5 in women); therefore, we merged mild cognitive impairment and normal cognitive function into a nonpossible dementia group when the data were analyzed.

\section{Measurement of BMI}

Height and weight were measured according to standardized procedures. BMI was calculated as weight in kilograms divided by height in meters-squared $\left(\mathrm{kg} / \mathrm{m}^{2}\right)$. Using BMI cutoffs for Asian populations recommended by WHO, we categorized BMI into 4 categories: underweight $(<18.5)$, normal weight $(18.5-$ 23.0 ), overweight (23.0-27.5) and obesity ( $\geq 27.5$ ) [27]. Considering the association changes in body composition with aging, cutoff points for underweight, normal weight, overweight and obesity might not be suitable for the long-lived sample, we also categorized BMI into 4 groups using quartile cutoff points: 1st $(<16.6), 2$ nd (16.6-18.9), 3rd (18.9-21.1) and 4th ( $\geq 21.1)$. In the sample, there were 6 men and 17 women who were bedridden, unable to stand, in whom weight and height could not be exactly measured, and for whom BMI could not be accurately calculated. To address this, these subjects were excluded when the data were analyzed $[28,29]$. 
Assessment of Covariates

The baseline examination included information on age (years), gender (male/female), educational levels (illiteracy, primary school, secondary school, college and postgraduate), smoking habits (yes or no), alcohol/smoking habits (yes or no), alcohol consumption (yes or no), tea consumption (yes or no), exercise (yes or no), serum uric acid (mol/l) and BMI $[23,24]$. Right arm blood pressure (sitting or recumbent position) was measured twice to the nearest $2 \mathrm{~mm} \mathrm{Hg}$ using a standard mercury sphygmomanometer (Korotkoff phases I and V) by trained nurses or physicians. Serum lipid/lipoprotein levels [including serum triglyceride (TG), total cholesterol, high-density lipoprotein (HDL) cholesterol and low-density lipoprotein cholesterol], fasting blood glucose and serum uric acid (SUA) were determined by standard laboratory techniques (performed by a technician in the biochemistry laboratory of Sichuan University). The other covariates were collected by using a general question.

Habits of smoking, alcohol consumption, tea consumption and exercise, which included former and current histories, were collected by using a general questionnaire. In the questionnaire, every item had 2 options: yes or no. We defined subjects with such habits as doing it almost everyday. Subjects were asked whether they had ever had habits of smoking, alcohol consumption, tea consumption and exercise, with the following choices of answers (1 only): never, did in the past, or currently. Among those who did, both currently or in the past, information was obtained on the average frequency of smoking, using alcohol, drinking tea and doing exercise and on the number of years they had these habits. The subjects who practiced these habits almost everyday during the recent year were classified as those with these habits currently, otherwise as without. The subjects, who had done these habits almost everyday for more than 2 years as of a year before, were classified as those with these habits previously, otherwise as without. Alcohol consumption included spirits, liqueurs, wine, sherry, martini, beer, lager, cider, stout, etc. Tea consumption included all types of tea. To assure reliability of this information, during the course of interviewing, at least 1 of the family members, who usually lived with the participant, took part in the interviewing and checked the filled-in questionnaire.

\section{Statistical Analysis}

All of the statistical analyses for this study were performed with the SPSS for Windows software package, version11.5 (SPSS Inc., Chicago, Ill., USA). Baseline characteristics were compared among different BMI subgroups using 1-way analysis of variance for continuous variable and Pearson's $\chi^{2}$ or Fisher's exact test (for which an expected cell count was $<5$ ) for categorical variables. Baseline characteristics were also compared between possible dementia and nonpossible dementia using unpaired Student's t test for continuous variables and Pearson's $\chi^{2}$ or Fisher's exact test (for which an expected cell count was $<5$ ) for categorical variables. Multiple logistic regression was used to estimate the OR and $95 \%$ CI of BMI as a function of increased risk for possible dementia. Considering the age, gender and educational levels were viewed as the general factors closely related with cognitive function and BMI, we adjusted them in Model 1. General or central adiposity, elevated blood pressure, dyslipidemia, hyperglycemia and hyperuricemia were viewed as the components of metabolic syndrome and these components might be with the similar mechanism in relation with cognitive function; thus, we adjusted fasting blood glucose, serum lipid/lipoprotein, blood pressure and SUA in Model 2. Lifestyles (including smoking, alcohol consumption, tea consumption and exercise) might relate with cognitive function and BMI, so we adjusted them in Model 3. Finally, we adjusted all these factors in Model 4. $\mathrm{p}<0.05$ was considered to be statistically significant, and all of the p values have 2 sides.

\section{Results}

\section{Baseline Characteristics, Cognitive Function and BMI}

Among the 638 participants, the mean age was 93.36 years, 64 were centenarians and 427 were women. Ninety percent of participants lived in the countryside. The mean MMSE scores were 15.57 (SD: 5.41). Only 35 volunteers scored higher than 24 , so we defined possible dementia as a score lower than 18. In the oldest-old sample, the prevalence of possible dementia was $54.6 \%$, the prevalence rate among males was $39.0 \%$ and $67.4 \%$ among females $(\mathrm{p}<0.001)$. In the sample, the prevalence of possible dementia was associated with educational levels $(\mathrm{p}<0.001)$. The subjects with possible dementia were younger in age than those without $(93.73 \pm 3.40$ vs. 93.17 \pm 3.28 years, $\mathrm{p}=0.040)$. Compared with subjects with possible dementia, those without were more likely to report the habit of tea consumption [current (53.1 vs. 49.2\%, $\mathrm{p}<0.001)$ and former (56.4 vs. 38.14\%, p < 0.001)]. Compared with subjects with possible dementia, those without had a lower total cholesterol level (4.06 \pm 0.86 vs. 4.20 $\pm 0.84 \mathrm{mmol} / \mathrm{l}, \mathrm{p}=0.036$; table 2 ).

In the oldest-old sample, the mean of BMI was 19.05 (SD: 3.64). Categorized using widely recognized cutoff points of BMI, 45.5, 43.4, 9.4 and $1.7 \%$ of the sample were in underweight, normal weight, overweight and obesity subgroups, respectively. There were different diastolic blood pressure $(\mathrm{p}=0.061)$, systolic blood pressure $(\mathrm{p}<$ $0.01)$, TG ( $p<0.01)$, HDL $(\mathrm{p}<0.01)$ and SUA $(\mathrm{p}<0.01)$ levels among these different subgroups. Categorized using quartile cutoff points, there were different diastolic blood pressure $(\mathrm{p}=0.040)$, systolic blood pressure $(\mathrm{p}<$ $0.01)$, TG ( $p<0.01)$, HDL $(\mathrm{p}<0.01)$ and SUA $(\mathrm{p}<0.01)$ levels among these different subgroups. Categorized using both widely recognized cutoff points and quartile cutoff points, there was no significant difference in lifestyles among these different subgroups (table 1).

\section{Cognitive Function in BMI Subgroups}

Categorized using widely recognized cutoff points in BMI, the difference in MMSE scores was nonsignificant $(15.73 \pm 5.29,15.52 \pm 5.53,14.70 \pm 5.33$ and $15.55 \pm$ 5.99 in underweight, normal weight, overweight and obe- 


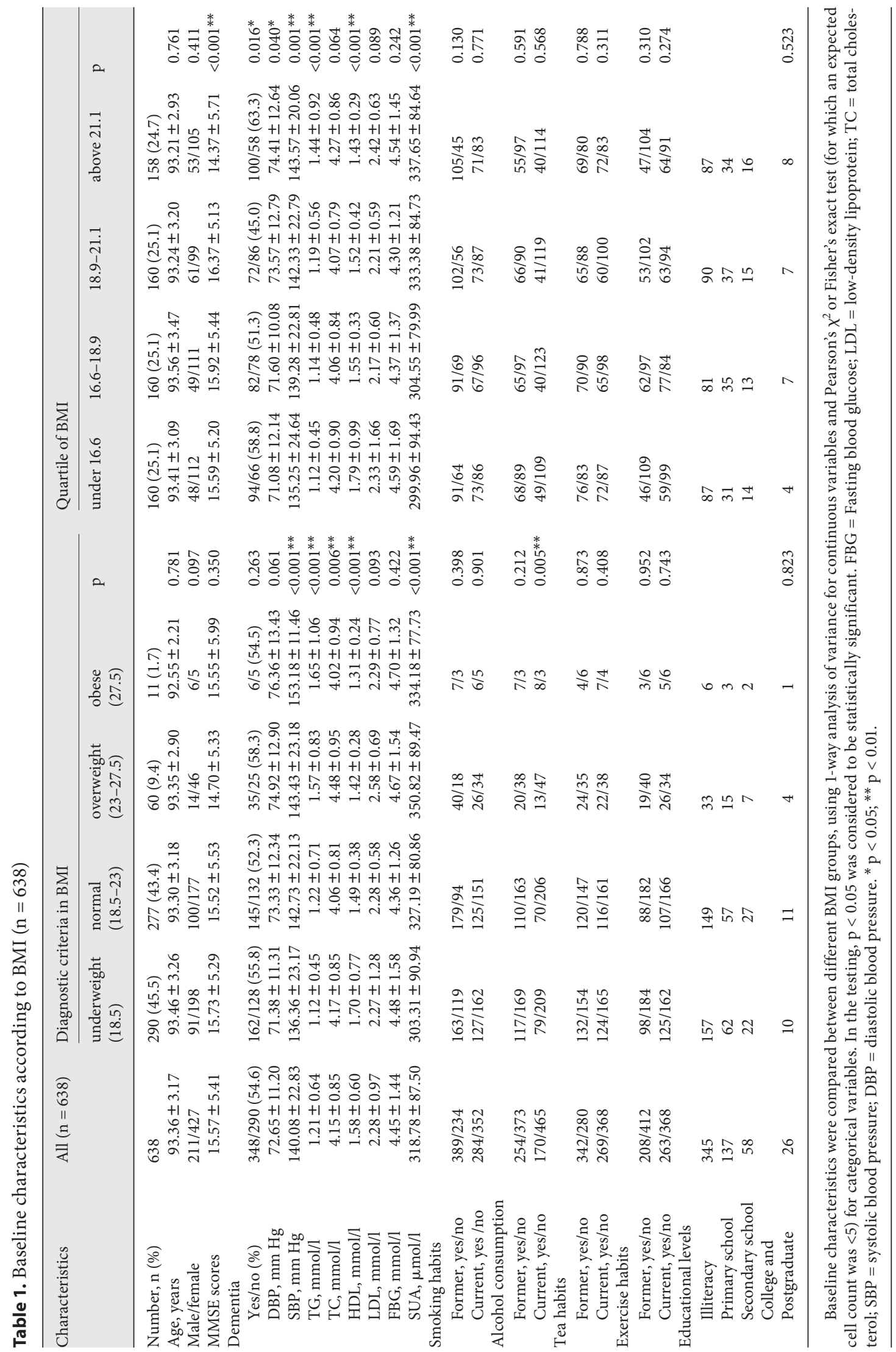


Table 2. Baseline characteristics according to cognitive function $(\mathrm{n}=638)$

\begin{tabular}{|c|c|c|c|c|}
\hline Characteristics & All $(n=638)$ & $\begin{array}{l}\text { Nonpossible } \\
\text { dementia }(n=290)\end{array}$ & $\begin{array}{l}\text { Possible dementia } \\
(\mathrm{n}=348)\end{array}$ & $\mathrm{p}$ \\
\hline Age, years & $93.52 \pm 3.37$ & $93.73 \pm 3.40$ & $93.17 \pm 3.28^{*}$ & $0.040^{*}$ \\
\hline Male/female & $211 / 427$ & $75 / 276$ & $136 / 151$ & $<0.001^{* *}$ \\
\hline $\mathrm{DBP}, \mathrm{mm} \mathrm{Hg}$ & $72.65 \pm 11.20$ & $72.08 \pm 12.08$ & $72.91 \pm 12.05$ & 0.388 \\
\hline $\mathrm{SBP}, \mathrm{mm} \mathrm{Hg}$ & $140.08 \pm 22.83$ & $139.71 \pm 23.31$ & $140.07 \pm 22.63$ & 0.862 \\
\hline $\mathrm{HDL}, \mathrm{mmol} / \mathrm{l}$ & $1.58 \pm 0.60$ & $1.59 \pm 0.66$ & $1.57 \pm 0.54$ & 0.222 \\
\hline $\mathrm{LDL}, \mathrm{mmol} / \mathrm{l}$ & $2.28 \pm 0.97$ & $2.27 \pm 0.59$ & $2.28 \pm 1.17$ & 0.810 \\
\hline $\mathrm{FBG}, \mathrm{mmol} / \mathrm{l}$ & $4.45 \pm 1.44$ & $4.45 \pm 1.52$ & $4.47 \pm 1.40$ & 0.883 \\
\hline SUA, $\mu \mathrm{mol} / \mathrm{l}$ & $318.78 \pm 87.50$ & $321.17 \pm 92.73$ & $316.88 \pm 82.53$ & 0.534 \\
\hline $\mathrm{BMI}$ & $19.05 \pm 3.64$ & $18.93 \pm 3.25$ & $19.11 \pm 3.85$ & 0.530 \\
\hline \multicolumn{5}{|l|}{ Smoking habits } \\
\hline Current, yes/no ${ }^{\mathrm{a}}$ & $170 / 465$ & $70 / 173$ & $100 / 292$ & 0.416 \\
\hline \multicolumn{5}{|l|}{ Tea habits } \\
\hline Former, yes/no ${ }^{\mathrm{a}}$ & $280 / 342$ & $132 / 102$ & $148 / 240$ & $<0.001^{* *}$ \\
\hline Current, yes/no ${ }^{\mathrm{a}}$ & $269 / 368$ & $129 / 114$ & $140 / 254$ & $<0.001^{* *}$ \\
\hline \multicolumn{5}{|l|}{ Exercise habits } \\
\hline Former, yes/no ${ }^{\mathrm{a}}$ & $208 / 412$ & $83 / 153$ & $125 / 259$ & 0.271 \\
\hline Current, yes/no ${ }^{\mathrm{a}}$ & $263 / 368$ & $109 / 132$ & $154 / 236$ & 0.093 \\
\hline \multicolumn{5}{|l|}{ Educational levels } \\
\hline Illiteracy & 345 & 146 & 199 & \\
\hline Primary school & 137 & 68 & 69 & \\
\hline Secondary school & 58 & 30 & 28 & \\
\hline College and postgraduate & 26 & 17 & 9 & $<0.001^{* *}$ \\
\hline
\end{tabular}

Baseline characteristics were compared between different BMI groups. ${ }^{*} \mathrm{p}<0.05$ and ${ }^{*} \mathrm{p}<0.01$ vs. nonpossible dementia, using $\chi^{2}$ or Fisher's exact test (where an expected cell count was $<5$ ) for categorical variables and unpaired Student's t test for continuous variables. $\mathrm{FBG}=$ Fasting blood glucose; $\mathrm{LDL}=$ low-density lipoprotein; $\mathrm{TC}=$ total cholesterol; $\mathrm{SBP}=$ systolic blood pressure; $\mathrm{DBP}=$ diastolic blood pressure.

${ }^{a} \mathrm{p}<0.05$ was considered to be statistically significant.

sity subgroups, respectively, $\mathrm{p}=0.350$ ) and the difference in prevalence of possible dementia was also nonsignificant $(55.8,52.3,58.3$ and $54.5 \%$ in underweight, normal weight, overweight and obesity subgroups respectively, $\mathrm{p}=0.263$; table 1 ).

Categorized using quartile cutoff points in BMI, there were significantly different MMSE scores $(15.59 \pm 5.20$, $15.92 \pm 5.44,16.37 \pm 5.13$ and $14.37 \pm 5.71$ in subgroups from the lowest to highest, respectively, $\mathrm{p}<0.001$ ) and prevalence of possible dementia $(58.8,51.3,45.0$ and $63.3 \%$ in subgroups from the lowest to highest, respectively, $\mathrm{p}=0.016)$. The 3rd quartile of BMI (18.9-21.1) showed the highest MMSE scores and the lowest preva- lence of possible dementia among the 4 subgroups (table 1). This showed an association between BMI and MMSE scores or the prevalence of possible dementia.

\section{BMI and the Risk for Dementia}

Categorized using widely recognized cutoff points of BMI, unadjusted and adjusted ORs for possible dementia among underweight, normal weight, overweight and obesity subgroups were nonsignificant.

Categorized using quartile cutoff points of BMI, the 3rd quartile (18.9-21.1) had significantly decreased ORs for possible dementia (OR: 0.589, 95\% CI: 0.383-0.935; OR: 0.614, 95\% CI: 0.371-0.918; OR: 0.602, 95\% CI: $0.376-$ 
Table 3. Effect of BMI on cognitive function in long-lived subjects

\begin{tabular}{|c|c|c|c|c|c|c|c|c|}
\hline \multirow[t]{2}{*}{ Characteristics } & \multicolumn{4}{|c|}{ Diagnostic criteria in BMI } & \multicolumn{4}{|c|}{ Quartile of BMI } \\
\hline & OR $(95 \% \mathrm{CI})$ & OR (95\% CI) & OR (95\% CI) & OR (95\% CI) & OR (95\% CI) & OR (95\% CI) & OR (95\% CI) & OR $(95 \% \mathrm{CI})$ \\
\hline Unadjusted & 1.000 (ref.) & $\begin{array}{l}0.955 \\
(0.913-1.315)\end{array}$ & $\begin{array}{l}1.087 \\
(0.762-1.534)\end{array}$ & $\begin{array}{l}0.981 \\
(0.851-1.384)\end{array}$ & 1.000 (ref.) & $\begin{array}{l}0.739 \\
(0.458-1.161)\end{array}$ & $\begin{array}{l}0.589 \\
(0.383-0.935)^{*}\end{array}$ & $\begin{array}{l}1.178 \\
(0.746-1.859)\end{array}$ \\
\hline Model 1 & 1.000 (ref.) & $\begin{array}{l}1.027 \\
(0.944-1.437)\end{array}$ & $\begin{array}{l}1.110 \\
(0.814-1.437)\end{array}$ & $\begin{array}{l}1.009 \\
(0.857-1.519)\end{array}$ & 1.000 (ref.) & $\begin{array}{l}0.731 \\
(0.463-1.157)\end{array}$ & $\begin{array}{l}0.614 \\
(0.371-0.918)^{*}\end{array}$ & $\begin{array}{l}1.248 \\
(0.785-2.001)\end{array}$ \\
\hline Model 2 & 1.000 (ref.) & $\begin{array}{l}0.974 \\
(0.901-1.276)\end{array}$ & $\begin{array}{l}0.935 \\
(0.813-1.368)\end{array}$ & $\begin{array}{l}0.888 \\
(0.636-1.568)\end{array}$ & 1.000 (ref.) & $\begin{array}{l}0.725 \\
(0.444-1.135)\end{array}$ & $\begin{array}{l}0.602 \\
(0.376-0.963)^{*}\end{array}$ & $\begin{array}{l}1.176 \\
(0.724-1.927)\end{array}$ \\
\hline Model 3 & 1.000 (ref.) & $\begin{array}{l}0.961 \\
(0.975-1.284)\end{array}$ & $\begin{array}{l}1.036 \\
(0.872-1.451)\end{array}$ & $\begin{array}{l}0.975 \\
(0.801-1.279)\end{array}$ & 1.000 (ref.) & $\begin{array}{l}0.759 \\
(0.498-1.270)\end{array}$ & $\begin{array}{l}0.660 \\
(0.411-0.991)^{*}\end{array}$ & $\begin{array}{l}1.470 \\
(0.903-2.391)\end{array}$ \\
\hline Model 4 & 1.000 (ref.) & $\begin{array}{l}1.107 \\
(0.963-1.385)\end{array}$ & $\begin{array}{l}1.145 \\
(0.877-1.494)\end{array}$ & $\begin{array}{l}1.150 \\
(0.835-1.468)\end{array}$ & 1.000 (ref.) & $\begin{array}{l}0.733 \\
(0.445-1.119)\end{array}$ & $\begin{array}{l}0.719 \\
(0.418-0.999)^{*}\end{array}$ & $\begin{array}{l}1.539 \\
(0.895-2.673)\end{array}$ \\
\hline
\end{tabular}

Adjusted multiple logistic regression was used to adjust for covariates; unadjusted: Wald $\chi^{2}$ with d.f. $=1$ was used. Model 1: adjustment made with age, gender and educational levels; Model 2: adjustment made with the other components of metabolic syndrome (blood pressure, serum lipid/lipoprotein, blood sugar, uric acid), age, gender and educational levels; Model 3: adjustment made with lifestyles (smoking habits, alcohol consumption, tea habits, exercise habits), age, gender and educational levels; Model 4: adjusted for all factors above.

${ }^{*} \mathrm{p}<0.05$.

0.963; OR: 0.660, 95\% CI: 0.411-0.991; OR: 0.719, 95\% CI: $0.418-0.999$ in the unadjusted model as well as adjusted Models 1, 2, 3 and 4, respectively).

\section{Discussion}

This study evaluated the association between BMI and cognitive function in long-lived subjects. In the crosssectional observations, categorized using quartile cutoff points of BMI, the 3rd subgroup (18.9-21.1) had lower risk for possible dementia and higher MMSE scores than the others; however, categorized using classification criteria (underweight, normal weight, overweight and obesity), normal weight (18.5-23.0) were no different in risk for possible dementia or MMSE scores than the others.

In the present study, according to classification criteria (underweight, normal weight, overweight and obesity) of $\mathrm{BMI}$ in the general population, there was a high prevalence of underweight (45.5\%), and there were more underweight subjects than those with normal weight. The sample was from a community population, with the prevalence of underweight in younger adults less than 5\% in the Chinese community population. Among elderly Chinese community dwellers (aged 60 years or above), the prevalence of underweight was lower than $10 \%[30,31]$. Aging was related with changes in body composition (in- cluding a decrease of BMI), and this finding was consistent with that of previous reports [13-16].

In the present study, subjects with BMI of 18.9-21.1 had lower risk for possible dementia than the others. However, MMSE scores or the prevalence of possible dementia in subjects with BMI of 18.5-23.0 was not different from the others. Those with BMI of 18.5-23.0 included $87(31.5 \%)$ with $21.1-23.0,160$ (57.7\%) with 18.9-21.1 and $30(10.8 \%)$ with $18.5-18.9$. Those with BMI of 18.523.0, but not from 18.9-21.1, removed the favorable effect on cognitive function of the BMI of 18.9-21.1. This indicated that among Chinese long-lived subjects, BMI around 20 (18.9-21.1) was the most favorable for prevention of dementia.

Focusing on the relationship between BMI and cognitive functioning, previous studies showed that the relationship between high BMI or obesity and cognitive status were inconsistent $[1,32-36]$, but most studies suggested that low BMI was related to dementia risk [33-36]. Our study provided evidence from Chinese community dwellers, and showed low and high BMI were both related to poorer cognitive function, even in cases where they did not meet the diagnostic criteria of underweight and overweight in BMI for Asian populations recommended by WHO.

In contrast to almost all previous studies, the standard used in this study was the MMSE rather than clinical di- 
agnosis of dementia, as an extensive clinical evaluation of 870 nonagenarians/centenarians in their home in this community of 2,311,709 inhabitants was impractical. The MMSE was only a screening test for dementia, which is also widely used to detect cognitive function. The MMSE score did not always reflect the exact cognitive function because it had been shown that it was sometimes influenced by age, gender and the level of education of the subject. In the present study, the subjects with better education had lower possible dementia. This finding was consistent with that of previous reports $[37,38]$. However, in the present study, after adjusting for age, gender and the level of education, BMI around 20 (18.9-21.1) still had a significantly decreased OR for possible dementia. These results strongly suggest that BMI of around 20 (18.9-21.1) was an important determinant factor of cognitive function in aged individuals. The finding has practical implications for interventions to prevent dementia. In our community-dwelling Chinese nonagenarians and centenarians, in order to maintain better cognitive function, $50 \%$ of them should have a higher BMI, and $25 \%$ should have a lower BMI, as the most appropriate BMI is around 20 (18.9-21.1).

The association between high BMI and cognitive function can be accounted for by the following: high BMI in long-lived subjects was related to increased BMI in middle age, which was viewed as a risk factor for a diagnosis of dementia a few decades later [1,2]; and together with obesity, hypertension, dyslipidemia, hyperuricemia and diabetes were viewed as metabolic syndrome components. Metabolic syndrome has been confirmed as the risk factor for dementia $[6-8,39]$. In the present study, the subjects with high BMI had high blood pressure, TG, SUA levels and low HDL levels, and those with possible dementia had higher total cholesterol levels than those without. Lifestyles such as smoking, alcohol, tea and exercise habits were related with both cognitive function and BMI $[40,41]$. In the present study, subjects with possible dementia had higher prevalence of tea habits than those without.

The association between low BMI and cognitive function can also be accounted for with weight loss in subjects with dementia [20-22], and changes in body composition (resulting in decreased BMI) and dementia were both related with aging [13-16]. Subjects who were both obese and who had dementia had a high mortality rate [42]. The high mortality rate in long-lived subjects might very likely remove those with high BMI and dementia, and leave moderate or severe dementia subjects with low BMI, enforcing the association between BMI and dementia.
Our study had some limitations that deserve mention. First, 870 subjects aged 90 years or older volunteered for the PLAD Study. Among these 870 volunteers, only 638 had nonmissing data for the 2 main variables involved in the current analyses. There might be selection biases. Because the MMSE relied heavily on visual and auditory abilities, especially at advanced ages, for subjects who were bedridden or unable to stand, it was difficult to be measure weight and height, and BMI could not be calculated. Among nonagenarians and centenarians, there was a high prevalence of visual or hearing impairment and being bedridden. We excluded those with visual or hearing impairment or being bedridden. However, the information from them might be unable to influence the practical implications of the present study. Second, because of the cross-sectional nature of this study, the subjects might change their diets and the conditions related to BMI. However, the lifestyles and food habits of the nonagenarians/centenarians were relatively stable and similar. Third, because of the cross-sectional nature of this study, we only concluded the association between BMI and dementia. We could not conduct causal conclusions on it. Fourth, since this is a part of the PLAD, there might be a survival bias. However, this is inherent in a study of individuals of this age group.

In conclusion, concerning longevity in Chinese, there is an association between BMI and cognitive function. BMI around 20 (18.9-21.1) is associated with the lowest risk of prevalence of possible dementia and the highest cognitive function scores.

\section{Acknowledgements}

This work was supported by the Discipline Construction Foundation of Sichuan University and by grants from the Project of Science and Technology Bureau of Sichuan Province (2006Z09006-4), and the Construction Fund for Subjects of West China Hospital of Sichuan University (XK05001). The authors thank the staff of the Department of Geriatrics Medicine, West China Hospital and Dujiangyan Hospital, and all participants (as well as their legal proxies) for their great contribution. 


\section{References}

1 Gustafson D: Adiposity indices and dementia. Lancet Neurol 2006;5:713-720.

-2 Jagust W: What can imaging reveal about obesity and the brain? Curr Alzheimer Res 2007;4:135-139.

-3 Gustafson D, Lissner L, Bengtsson C, Björkelund C, Skoog I: A 24-year follow-up of body mass index and cerebral atrophy. Neurology 2004;63:1876-1881.

4 Ward MA, Carlsson CM, Trivedi MA, Sager MA, Johnson SC: The effect of body mass index on global brain volume in middle-aged adults: a cross sectional study. BMC Neurol 2005;5:23.

5 Jagust W, Harvey D, Mungas D, Haan M: Central obesity and the aging brain. Arch Neurol 2005;62:1545-1548.

6 Gustafson D, Rothenberg E, Blennow K, Steen B, Skoog I: An 18-year follow-up of overweight and risk of Alzheimer disease. Arch Intern Med 2003;163:1524-1528.

>7 Kivipelto M, Ngandu T, Fratiglioni L, Viitanen M, Kåreholt I, Winblad B, Helkala EL, Tuomilehto J, Soininen H, Nissinen A: Obesity and vascular risk factors at midlife and the risk of dementia and Alzheimer disease. Arch Neurol 2005;62:1556-1560.

$\checkmark 8$ Whitmer RA, Gunderson EP, Barrett-Connor E, Quesenberry CP Jr, Yaffe K: Obesity in middle age and future risk of dementia: a 27 year longitudinal population based study. BMJ 2005;330:1360.

-9 Elias MF, Elias PK, Sullivan LM, Wolf PA, D'Agostino RB: Lower cognitive function in the presence of obesity and hypertension: the Framingham Heart Study. Int J Obes Relat Metab Disord 2003;27:260-268.

$\checkmark 10$ Elias MF, Elias PK, Sullivan LM, Wolf PA, D'Agostino RB: Obesity, diabetes and cognitive deficit: the Framingham Heart Study. Neurobiol Aging 2005;26(Suppl 1):11-16.

11 Waldstein SR, Katzel LI: Interactive relations of central versus total obesity and blood pressure to cognitive function. Int $J$ Obes (Lond) 2006;30:201-207.

12 Gunstad J, Paul RH, Cohen RA, Tate DF, Spitznagel MB, Gordon E: Elevated body mass index is associated with executive dysfunction in otherwise healthy adults. Compr Psychiatry 2007;48:57-61.

$\checkmark 13$ Horber FF, Gruber B, Thomi F, Jensen EX, Jaeger P: Effect of sex and age on bone mass, body composition and fuel metabolism in humans. Nutrition 1997;13:524-534.

-14 Snijder MB, van Dam RM, Visser M, Seidell JC: What aspects of body fat are particularly hazardous and how do we measure them? Int J Epidemiol 2006;35:83-92.

15 Wang Q, Hassager C, Ravn P, Wang S, Christiansen C: Total and regional body-composition changes in early postmenopausal women: age-related or menopause-related? Am J Clin Nutr 1994;60:843-848.
16 Zamboni M, Armellini F, Harris T, et al: Effects of age on body fat distribution and cardiovascular risk factors in women. Am J Clin Nutr 1997;66:111-115.

17 Ohlson LO, Larsson B, Svardsudd K, et al: The influence of body fat distribution on the incidence of diabetes mellitus. 13.5 years of follow-up of the participants in the study of men born in 1913. Diabetes 1985;34:10551058.

18 Okosun IS, Cooper RS, Rotimi CN, Osotimehin B, Forrester T: Association of waist circumference with risk of hypertension and type 2 diabetes in Nigerians, Jamaicans, and African-Americans. Diabetes Care 1998;21: 1836-1842.

19 Boyko EJ, Fujimoto WY, Leonetti DL, Newell-Morris L: Visceral adiposity and risk of type 2 diabetes: a prospective study among Japanese Americans. Diabetes Care 2000;23: 465-471.

20 Holm B, Söderhamn O: Factors associated with nutritional status in a group of people in an early stage of dementia. Clin Nutr 2003; 22:385-389.

21 Keller HH, Gibbs AJ, Boudreau LD, Goy RE, Pattillo MS, Brown HM: Prevention of weight loss in dementia with comprehensive nutritional treatment. J Am Geriatr Soc 2003;51:945-952.

-22 Mazzali G, Bissoli L, Gambina S, Residori L, Pagliari P, Guariento S, Sun M, Broggio E, Bosello O, Zamboni M: Energy balance in Alzheimer's disease. Nutr Health Aging 2002;6:247-253.

23 Huang CQ, Dong BR, Zhang YL, Wu HM, Liu QX, Flaherty JH: Moderate or severe dementia and hypertension among Chinese nonagenarians and centenarians. Hypertens Res 2009;32:554-558.

24 Huang CQ, Dong BR, Wu HM, Zhang YL, Wu JH, Lu ZC, Flaherty JH: Association of moderate or severe dementia with serum lipid/lipoprotein among Chinese nonagenarians and centenarians. Dement Geriatr Cogn Disord 2009;27:111-116.

25 Holtsberg PA, Poon LW, Noble CA, Martin P: Mini-Mental State Exam status of community-dwelling cognitively intact centenarians. Int Psychogeriatr 1995;7:417-427.

26 Reischies FM, Geiselmann B: Age-related cognitive decline and vision impairment affecting the detection of dementia syndrome in old age. Br J Psychiatry 1997;171:449-451.

27 WHO Expert Consultation: Appropriate body-mass index for Asian populations and its implications for policy and intervention strategies. Lancet 2004;363:157-163.

28 Drøyvold WB, Nilsen TI, Krüger O, Holmen TL, Krokstad S, Midthjell K, Holmen J: Change in height, weight and body mass index: longitudinal data from the HUNT Study in Norway. Int J Obes (Lond) 2006;30: 935-939.
29 Scholtens S, Brunekreef B, Visscher TL, Smit HA, Kerkhof M, de Jongste JC, Gerritsen J, Wijga AH: Reported versus measured body weight and height of 4-year-old children and the prevalence of overweight. Eur J Public Health 2007;17:369-374.

30 Lau EM, Lynn HS, Woo JW, Kwok TC, Melton LJ 3rd: Prevalence of and risk factors for sarcopenia in elderly Chinese men and women. J Gerontol A Biol Sci Med Sci 2005; 60:213-216.

31 Chan KM, Pang WS, Ee CH, Ding YY, Choo P: Self-perception of health among elderly community dwellers in Singapore. Ann Acad Med Singapore 1998;27:461-467.

- 32 Kuo HK, Jones RN, Milberg WP: Cognitive function in normal-weight, overweight, and obese older adults: an analysis of the Advanced Cognitive Training for Independent and Vital Elderly cohort. J Am Geriatr Soc 2006;54:97-103.

33 Nourhashemi F, Deschamps V, Larrieu S: The PAQUID Study. Body mass index and incidence of dementia. Neurology 2003;60: 117-119.

34 Barrett-Connor E, Edelstein SL, CoreyBloom J: Weight loss precedes dementia in community-dwelling older adults. J Am Geriatr Soc 1996;44:1147-1152.

35 Stewart R, Masaki K, Xue QL: A 32-year prospective study of change in body weight and incident dementia: the Honolulu-Asia Aging Study. Arch Neurol 2005;62:55-60.

36 Buchman AS, Wilson RS, Bienias JL: Change in body mass index and risk of incident Alzheimer disease. Neurology 2005;65:892897.

37 Tombaugh TN, McIntyre NJ: The MiniMental State Examination: A comprehensive review. J Am Geriatr Soc 1992;40:922-935.

38 Uhlmann RF, Larson EB: Effect of education on the mini-mental state examination as a screening test for dementia. J Am Geriatr Soc 1991;39:876-880.

- 39 van den Berg E, Biessels GJ, de Craen AJ, Gussekloo J, Westendorp RG: The metabolic syndrome is associated with decelerated cognitive decline in the oldest old. Neurology 2007;69:979-985.

40 Huang CQ, Dong BR, Zhang YL, Wu HM, Liu QX: Association of moderate or severe dementia with smoking, alcohol consumption, tea consumption, and exercise among Chinese nonagenarians/centenarians. Cogn Behav Neurol 2009;22:190-196.

41 Feng L, Gwee X, Kua EH, Ng TP: Cognitive function and tea consumption in community dwelling older Chinese in Singapore. J Nutr Health Aging 2010;14:433-438.

42 Osher E, Stern N: Obesity in elderly subjects: in sheep's clothing perhaps, but still a wolf! Diabetes Care 2009;32(Suppl 2):S398-S402. 